\title{
FORMULASI DAN UJI STABILITAS KRIM ASAM KOJAT DALAM PEMBAWA VESIKEL ETOSOM
}

\author{
Sandra Aulia Mardikasari ${ }^{1}$, Nur Illiyyin Akib $^{2}$, Suryani ${ }^{2}$, Muhammad Handoyo Sahumena ${ }^{2}$, La Ode \\ Muhammad Jerni ${ }^{2}$ \\ ${ }^{1}$ Fakultas Farmasi, Universitas Hasanuddin, Makassar, 90245, Indonesia \\ ${ }^{2}$ Fakultas Farmasi, Universitas Haluoleo, Kendari, 93232, Indonesia
}

Kata Kunci :

Asam kojat, etosom, uji stabilitas, cycling test, centrifugal test

\section{ABSTRAK}

Asam kojat diketahui memiliki efektivitas untuk mencerahkan kulit. Tetapi asam kojat bersifat hidrofilik, sehingga sulit berpenetrasi ke dalam kulit oleh karena itu diperlukan sistem penghantaran etosom untuk meningkatkan penetrasi asam kojat dalam bentuk sediaan krim untuk memudahkan pengaplikasiannya di kulit. Penelitian ini bertujuan untuk membuat formula krim etosom asam kojat menggunakan kombinasi emulgator tween 80 dan span 80 dalam berbagai konsentrasi, serta menguji kestabilan fisik sediaan krim. Uji stabilitas krim dilakukan menggunakan metode cycling test dan centrifugal test. Metode cycling test meliputi pengamatan organoleptik, tipe krim, $\mathrm{pH}$, viskositas, ukuran globul, daya sebar dan homogenitas krim, sedangkan metode centrifugal test dilakukan menggunakan alat sentrifugasi untuk melihat terjadinya pemisahan fase pada krim. Hasil penelitian menunjukkan adanya perbedaan nilai organoleptik, pH, viskositas, ukuran globul dan daya sebar namun tidak terjadi pemisahan fase setelah uji centrifugal test. Sehingga diperoleh krim yang paling stabil yaitu pada formula krim dengan konsentrasi emulgator 3\%, memiliki nilai organoleptik yang baik, tipe krim m/a, pH 5,24, viskositas $22.200 \mathrm{cPs}$, ukuran globul berkisar $0,1-0,3 \mu \mathrm{m}$, daya sebar $4,1 \mathrm{~cm}^{2}$, krim yang homogen, dan tidak terjadi pemisahan fase setelah uji sentrifugasi. Hasil penelitian ini menunjukkan etosom asam kojat dapat diformulasi menjadi sediaan krim yang stabil.

\section{PENDAHULUAN}

Kulit merupakan organ yang menutupi seluruh tubuh manusia yang berfungsi untuk melindungi dari pengaruh luar. Kerusakan pada kulit akan mengganggu kesehatan maupun penampilan, sehingga kulit perlu dilindungi dan dijaga kesehatannya. Kulit perlu perhatian khusus terutama pada bagian wajah, terbukti dengan semakin banyaknya produk-produk kosmetik pemutih kulit yang menjanjikan konsumen, dengan warna kulit yang lebih cerah setelah pemakaian produk dalam jangka waktu tertentu. Pada sediaan kosmetika jenis pemutih atau pencerah kulit umumnya digunakan bahan-bahan penghambat hiperpigmentasi kulit $(1,2)$.

Hiperpigmentasi adalah kelainan pigmentasi kulit yang terjadi karena peningkatan sintesis melanin atau distribusi melanin yang tidak merata akibat paparan sinar UV sehingga terbentuk noda hitam di kulit (3). Upaya untuk mencegah terjadinya hiperpigmentasi adalah dengan menghambat aktivitas enzim tirosinase sehingga mengganggu konversi tirosin menjadi melanin (4). Tirosinase adalah enzim utama yang terlibat dalam biosintesis melanin. Inhibisi terhadap enzim tirosinase untuk mengatur metabolisme pigmentasi. Senyawa inhibitor tirosinase digunakan sebagai bahan pencerah kulit (5). Salah satunya senyawa inhibitor tirosinase adalah asam kojat.

Asam kojat merupakan senyawa kimia yang efektif mencerahkan kulit dengan cara mengatasi gangguan hiperpigmentasi kulit $(6,7)$. Asam kojat menghambat kerja enzim tyrosinase, dengan berikatan pada sisi aktif dari enzim tyrosinase sehingga tidak terjadi hiperpigmentasi (8). Namun asam kojat bersifat hidrofilik, sehingga sulit berpenetrasi ke dalam kulit. Asam kojat akan memberi efek sebagai pemutih jika menembus stratum corneum dan mencapai lapisan basal (9). Asam kojat memiliki efek inhibisi dan kestabilan yang paling besar dalam mencegah hiperpigmentasi kulit (10), sehingga penting untuk memformulasi asam kojat sebagai produk kosmeseutikal pemutih dengan cara meningkatkan efek penjerapan asam kojat melewati stratum corneum. Diperlukan sistem pembawa yang dapat menghantaran zat aktif untuk menembus lapisan kulit. Salah satu sistem penghantaran transdermal yang dapat digunakan adalah Etosom (11).

Etosom merupakan vesikel lipid lunak yang terdiri dari fosfolipid, alkohol dalam konsentrasi yang relatif tinggi (20-45 \%) dan air. Etosom memiliki kemampuan yang tinggi untuk mengubah struktur kulit sehingga mampu membawa obat meresap ke dalam kulit secara utuh (12). Etosom dapat diformulasikan dalam bentuk sediaan semipadat berupa gel dan krim $(11,13)$

Sediaan dalam bentuk krim banyak digunakan karena mempunyai beberapa keuntungan dibandingkan dengan sediaan salep, gel maupun pasta, diantaranya lebih mudah diaplikasikan, lebih nyaman digunakan pada wajah, tidak lengket dan mudah dicuci dengan air. Sediaan krim yang baik harus memenuhi syarat tertentu seperti memiliki kestabilan fisik yang memadai (14). Oleh karena itu dalam penelitian ini dilakukan formulasi suspensi etosom asam kojat menjadi sediaan krim, kemudian uji stabilitas sediaan krim etosom asam kojat berupa pengujian Cycling test, pengamatan organoleptik, penentuan tipe emulsi, penentuan $\mathrm{pH}$, dan penentuan viskositas, pengujian dan centrifugal test. 


\section{METODE PENELITIAN}

\section{Prosedur Kerja}

\section{Preparasi Etosom Asam Kojat}

Asam kojat 2\% dipreparasi menggunakan metode panas. Fosfatidilkolin 2\% dicampurkan ke dalam air suling di atas hot plate pada suhu $40^{\circ} \mathrm{C}$ hingga menghasilkan campuran (a). Etanol 45\% dan propilen glikol 1\% dicampur dalam wadah yang berbeda menghasilkan campuran (b). Campuran (b) dimasukkan dalam campuran (a) dan diaduk menggunakan magnetic stirrer dengan kecepatan 700 rpm selama 5 menit hingga membentuk campuran (c). Asam kojat 2\% dilarutkan dalam air suling secukupnya dan ditambahkan pada campuran (c). Air suling ditambahkan sedikit demi sedikit hingga cukup $100 \%$ dan pengadukan dilanjutkan selama 5 menit dengan kecepatan 700 rpm. Ukuran vesikel etosom dapat diperkecil dengan menggunakan metode sonikasi selama 15 menit. Suspensi etosom yang telah terbentuk kemudian didinginkan pada suhu ruang dan selanjutnya disimpan dalam lemari pendingin (15)

Persiapan Krim Asam Kojat dalam Pembawa Vesikel Etosom

Formulasi krim etosom asam kojat dibuat sebanyak 15gram mengandung $1 \%$ asam kojat dengan memvariasikan komposisi kombinasi emulgator Tween 80 dan Span 80

\begin{tabular}{|c|c|c|c|c|c|c|}
\hline Bahan & $\begin{array}{l}\text { F } 1 \\
\text { (\%) }\end{array}$ & $\begin{array}{l}\text { F2 } \\
\text { (\%) }\end{array}$ & $\begin{array}{l}\text { F } 3 \\
\text { (\%) }\end{array}$ & $\begin{array}{l}\text { F } 4 \\
\text { (\%) }\end{array}$ & $\begin{array}{l}\text { F } 5 \\
\text { (\%) }\end{array}$ & Fungsi \\
\hline Asam Kojat & 1 & 1 & 1 & 1 & 1 & Zat aktif \\
\hline Gliserin & 10 & 10 & 10 & 10 & 10 & Humektan \\
\hline Parafin cair & 5 & 5 & 5 & 5 & 5 & Emolien \\
\hline Setil alcohol & 5 & 5 & 5 & 5 & 5 & Pengental \\
\hline HPMC & 2 & 2 & 2 & 2 & 2 & Pengental \\
\hline $\begin{array}{l}\text { Kombinasi } \\
\text { Tween } 80 \\
\text { dan Span } 80\end{array}$ & 1 & 3 & 5 & 7 & 9 & Emulgator \\
\hline BHT & 0.1 & 0.1 & 0.1 & 0.1 & 0.1 & Antioksidan \\
\hline Metil paraben & 0,18 & 0,18 & 0,18 & 0,18 & 0,18 & Pengawet \\
\hline
\end{tabular}

Pembuatan Krim Asam Kojat dalam Pembawa Vesikel Etosom

Fase minyak dibuat dengan melebur berturut-turut setil alkohol, kemudian ditambahkan paraffin cair, propil paraben, BHT dan span 80, kemudian dipertahankan pada suhu $70-75^{\circ} \mathrm{C}$. Fase air dibuat dengan melarutkan metil paraben dalam air yang dipanaskan pada suhu $90^{\circ} \mathrm{C}$ dan ditambahkan gliserin. Kemudian ditambahkan tween 80 dan suhu dipertahankan $70^{\circ} \mathrm{C}$. Krim dibuat dengan mencampurkan fase minyak ke dalam fase air di bawah pengadukan konstan pada kecepatan $600 \mathrm{rpm}$, kemudian dimasukkan HPMC yang telah dikembangkan. Setelah tercampur homogen, suhu diturunkan sampai $30^{\circ} \mathrm{C}$ kemudian suspensi etosom ditambahkan sambil diaduk menggunakan mixer (16).

\section{Uji Stabilitas Krim}

\section{Cycling Test}

Salah satu pengujian stabilitas adalah dengan metode Cycling test. Satu siklus sediaan krim disimpan pada suhu $4{ }^{\circ} \mathrm{C}$ selama 24 jam lalu dikeluarkan dan ditempatkan pada suhu $40^{\circ} \mathrm{C}$ selama 24 jam. Percobaan ini diulang sebanyak 6 siklus. Kondisi fisik krim dibandingkan selama percobaan dengan sediaan sebelumnya (17).

\section{Pengamatan Organoleptik}

Pengamatan organoleptis dapat dinilai dari tekstur sediaan meliputi perubahan warna dan bau krim. Pengamatan dilakukan terhadap krim yang baru dibuat dan telah disimpan (18). Krim yang stabil harus menunjukkan karakter yang sama berupa warna dan bau yang sama sebelum dan setelah kondisi penyimpanan dipercepat (19).

\section{Uji pH Krim}

Pemeriksaan $\mathrm{pH}$ menggunakan alat pH-meter yang dikalibrasi menggunakan larutan dapar $\mathrm{pH} 7$ dan $\mathrm{pH} 4$. Elektroda $\mathrm{pH}$-meter dicelupkan ke dalam krim, jarum $\mathrm{pH}$ meter dibiarkan bergerak sampai menunjukkan posisi tetap, $\mathrm{pH}$ yang ditunjukkan dicatat (20).

\section{Uji Tipe Krim}

Pengujian tipe dilakukan dengan penambahan metilen biru, dimana sejumlah sediaan krim diletakan pada kaca arloji, kemudian tambahkan 1 tetes metil biru, kemudian diaduk dengan batang pengaduk. Bila metil biru tersebar merata berarti tipe krim yang dihasilkan adalah minyak dalam air (m/a). Bila timbul bintik-bintik biru maka krim yang dihasilkan berupa tipe krim air dalam minyak (a/m) (21).

\section{Uji Viskositas}

Viskositas formulasi ditentukan oleh Rion Rotor Viscotester VT-04 menggunakan spindle no. 3. Krim dimasukkan dalam gelas beker, lalu spindle dicelupkan ke dalam krim jangan sampai menyentuh wadah. Kemudian alat viskometer dinyalakan dan dilihat pada viskosimeter berapa skala yang ditunjuk (22).

\section{Pengamatan Ukuran Globul}

Pengamatan ukuran globul atau tetes terdispersi dilakukan dengan menggunakan mikroskop mikrometer. Caranya dengan meneteskan krim pada objek gelas kemudian ditutup dengan dek gelas dan setelah diperoleh perbesaran dan perbandingan skala mikrometer okuler dan mikrometer obyektif yang sesuai maka diamati rentang ukuran partikel tetes terdispersinya (14)

\section{Uji Daya Sebar Krim}

Ditimbang 50gram krim dan letakkan di tengah kaca bulat. Sebelum ditimbang dahulu kaca satunya dan letakkan kaca tersebut di atas krim dan biarkan selama 1 menit, kemudian diukur berapa diameter krim yang menyebar dengan mengambil panjang rata-rata diameter dari beberapa sisi. Jumlah beban yang ditambahkan sebanyak 100gram dengan penambahan setiap beban sebanyak 50 gram. Biarkan krim selama 1 menit, kemudian dicatat diameter krim pada empat sisi dan ditentukan luas penyebaran krim (23).

\section{Uji Homogenitas}

Pemeriksaan homogenitas dilakukan dengan menggunakan gelas objek dimana sejumlah sediaan krim dioleskan pada sekeping kaca atau bahan transparan lainnya yang cocok, sediaan harus menunjukan susunan yang homogen dan tidak terlihat adanya butiran kasar (21).

\section{Centrifugal Test}

Uji Centrifugal test dilakukan terhadap krim yang baru dibuat. Pengujian dilakukan dengan cara memasukkan sediaan krim dalam tabung sentrifugasi, kemudian diputar pada kecepatan $6.000 \mathrm{rpm}$ selama 30 menit, kemudian diamati bentuk fisik krim. Krim yang tidak stabil ditandai dengan terjadinya pemisahan fase (24) 


\section{HASIL DAN PEMBAHASAN}

\section{Pengamatan Organoleptik}

Pengamatan organoleptik menunjukkan bahwa formula krim etosom asam kojat yang dibuat selain formula 2, mengalami perubahan konsistensi, warna dan bau setelah kondisi penyimpanan dipercepat (Cycling test). Hal ini dikarenakan penyimpanan krim pada suhu panas akan menyebabkan asam lemak tak jenuh dari fase minyak dan etosom mengalami oksidasi. Kerusakan lemak yang utama adalah timbulnya bau dan rasa tengik yang disebut proses ketengikan atau oksidasi (25). Proses oksidasi dapat terjadi pada suhu kamar dan selama periode cycling test menggunakan suhu tinggi (25). Pada formula 1 terjadi oksidasi akibat pecahnya droplet emulsi karena konsentrasi emulgator yang digunakan terlalu rendah yaitu $1 \%$ sehingga komponen etosom keluar dari dalam droplet emulsi dan teroksidasi. Sedangkan pada formula 2 tidak terjadi perubahan organoleptik yang menunjukkan bahwa pada konsentrasi emulgator $3 \%$ dapat mempertahankan kestabilan krim selama cycling test.

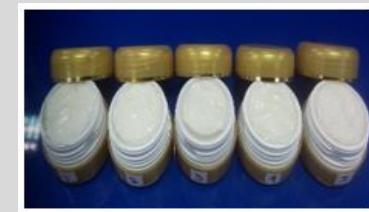

(A)

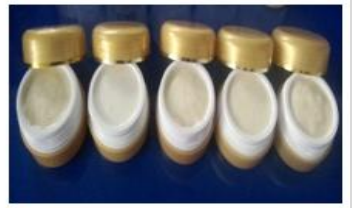

(B)
Gambar 2. Sediaan krim etosom asam kojat (A) sebelum Cycling test ; (B) Setelah Cycling test

Pada masing-masing formula 3, 4 dan 5 juga mengalami oksidasi, hal ini terjadi karena semakin tinggi konsentrasi emulgator yang digunakan mengandung rantai asam lemak ester yang mudah teroksidasi (26), sehingga terjadi kontak antara sejumlah oksigen dengan ikatan rangkap pada minyak (25).

Uji pH Krim

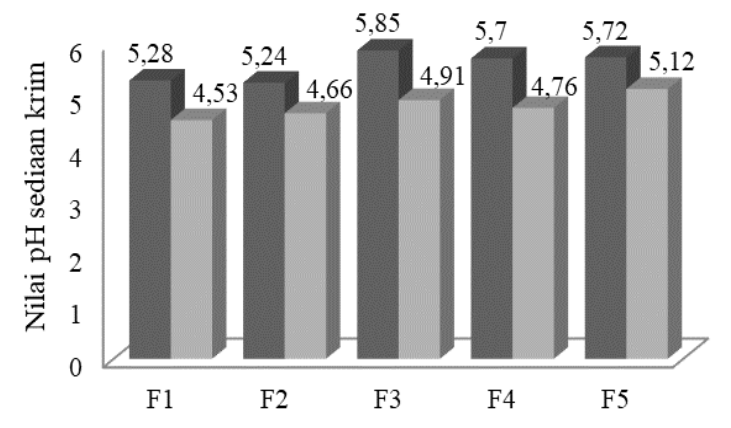

Gambar 2. Grafik Hasil Pengukuran $\mathrm{pH}$ sediaan krim etosom asam kojat sebelum cycling test $(\square)$ dan ( $\square$ ) setelah cycling test

Hasil pengujian $\mathrm{pH}$ krim etosom asam kojat sesuai dengan ketetapan nilai pH sediaan kosmetik berkisar 4,5-6,5 (27). Hal ini menunjukkan bahwa formula krim etosom asam kojat aman untuk digunakan pada kulit. $\mathrm{pH}$ yang terlalu asam atau basa dapat menyebabkan kulit menjadi kering dan mengalami iritasi karena terjadinya kerusakan mantel asam pada lapisan stratum corneum (28). Nilai pH krim etosom asam kojat cenderung menunjukkan penurunan setelah dilakukan Cycling test. Penurunan nilai $\mathrm{pH}$ dapat terjadi karena adanya zat-zat yang terurai dalam sediaan krim yang terjadi selama cycling test, terutama terjadinya penguraian asam-asam lemak tak jenuh dari fase minyak pada krim (29). Namun masih berada pada rentang pH fisiologis kulit, sehingga masih tetap aman untuk digunakan.
Uji Tipe Krim

\begin{tabular}{ccc}
\multicolumn{3}{l}{ Tabel 1. Hasil pengamatan tipe krim } \\
\hline Formula & Sebelum cycling test & Setelah cycling test \\
\hline 1 & $\mathrm{~m} / \mathrm{a}$ & $\mathrm{m} / \mathrm{a}$ \\
2 & $\mathrm{~m} / \mathrm{a}$ & $\mathrm{m} / \mathrm{a}$ \\
3 & $\mathrm{~m} / \mathrm{a}$ & $\mathrm{m} / \mathrm{a}$ \\
4 & $\mathrm{~m} / \mathrm{a}$ & $\mathrm{m} / \mathrm{a}$ \\
5 & $\mathrm{~m} / \mathrm{a}$ & $\mathrm{m} / \mathrm{a}$ \\
\hline
\end{tabular}

Uji Viskositas

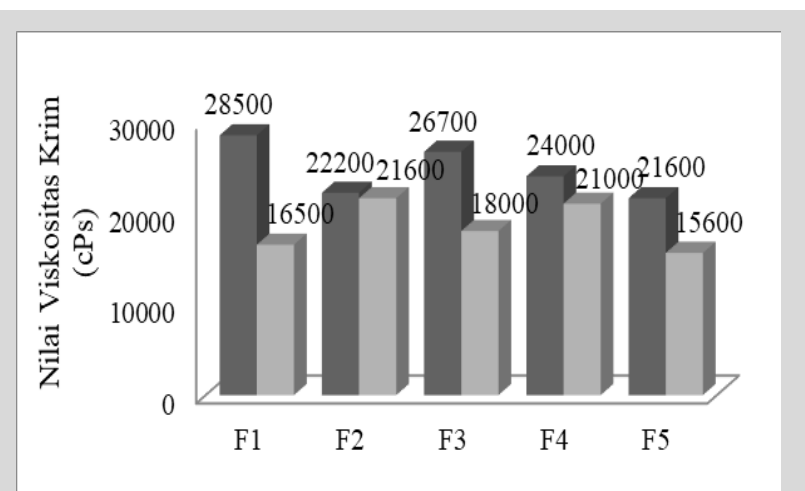

Gambar 3. Grafik hasil pengukuran viskositas sediaan krim etosom asam kojat sebelum cycling test $(\square)$ dan ( $\square$ ) sesudah cycling test

Hasil pengukuran viskositas diperoleh tiap formula setelah uji cycling test menunjukkan kecenderungan mengalami penurunan viskositas dibandingkan sebelum cycling test. Menurut Swastika dkk. (2013) penurunan viskositas yang terlalu tinggi menunjukkan ketidakstabilan sediaan krim sebagaimana yang terjadi pada formula 1, 3, 4 dan 5 . Sedangkan pada formula 2 sedikit mengalami penurunan nilai viskositas yang menunjukkan kestabilan yang baik. Penurunan viskositas ini dapat disebabkan oleh kenaikan ukuran diameter partikel yang menyebabkan luas permukaannya semakin kecil yang kemudian mengakibatkan viskositas menjadi turun (21). Penurunan nilai viskositas pada formula 1, 3, 4 dan 5 kemungkinan besar berhubungan dengan pemisahan fase yang menunjukkan ketidakstabilan krim (32).

\section{Pengamatan Ukuran Globul}

Pengukuran diameter globul diperoleh hasil yang menunjukkan bahwa ukuran diameter globul tidak terjadi perubahan yang signifikan. Kisaran rata-rata ukuran diameter globul dari formula krim sebelum penyimpanan adalah 0,1-0,8 $\mu \mathrm{m}$. Ukuran globul masing-masing formula sedikit mengalami perubahan diameter setelah penyimpanan yaitu berkisar antara 0,1-1,05 $\mu \mathrm{m}$ namun masih berada dalam batas rentang ukuran globul suatu emulsi yang baik, yaitu 0,1-100 $\mu \mathrm{m}$ (33). Hasil pengamatan formula 1 setelah proses penyimpanan memperlihatkan gambaran globul yang tidak beraturan dan sebagaian besar globul-globul emulsi yang terbentuk mengalami kerusakan. Hal ini mengindikasikan krim mengalami coalescence dan kristalisasi asam lemak yang disebabkan faktor perubahan suhu cycling test. Pada formula 4 dan 5 juga memperlihatkan adanya sebagian kecil globul emulsi yang mengalami kerusakan dan peningkatan ukuran globul, menurut Swastika dkk. (2013) hal ini dapat menyebabkan ketidakstabilan emulsi dan pemisahan fase akibat kurangnya kerapatan globul karena rusak dan meningkatnya ukuran globul emulsi sehingga dapat terjadi pemisahan fase. Penyimpanan krim pada suhu tinggi mengakibatkan peningkatan energi kinetik dari butiran-butiran fase terdispersi sehingga memudahkan penggabungan antar fase terdispersi tersebut membentuk suatu coalescence (31), seperti yang terjadi pada formula 1, 4, dan 5. Sedangkan pada formula 2 dan 3 tidak menunjukkan 
adanya kerusakan dan perubahan ukuran globul sehingga pada formula ini mengindikasikan tidak akan terjadi pemisahan fase.

\section{Uji Daya Sebar Krim}

Daya sebar berkaitan dengan sifat penyebaran krim ketika digunakan pada sediaan topikal. Hasil pengamatan menunjukkan daya sebar krim setelah uji cycling test mengalami peningkatan. Daya sebar krim rata-rata sebelum dan setelah Cycling test berkisar antara 4,1-7,2 $\mathrm{cm}^{2}$. Kelima formula menunjukkan kecenderungan yang sama yaitu mengalami peningkatan daya sebar selama penyimpanan. Hal ini disebabkan karena peningkatan daya sebar berbanding lurus dengan nilai viskositas yang ditunjukkan pada setiap formula. Viskositas krim tersebut semakin menurun selama penyimpanan sehingga tahanan cairan untuk mengalir semakin berkurang sehingga daya sebar krim meningkat (30). Semakin besar daya sebar, luas permukaan kulit yang kontak dengan krim akan semakin luas dan zat aktif akan terdistribusi dengan baik. Krim yang baik memiliki daya sebar yang besar sehingga dapat diaplikasikan pada permukaan kulit yang luas tanpa penekanan yang berlebihan. Kemampuan daya sebar krim dilihat dari diameter sebaran krim yang dihasilkan.

\section{Uji Homogenitas}

Hasil pengamatan homogenitas menunjukkan bahwa tidak terdapat gumpalan-gumpalan kasar pada kelima formula sediaan krim etosom asam kojat. Semua formula krim menunjukkan homogenitas yang sangat baik. Homogenitas berpengaruh terhadap efektivitas terapi karena berhubungan dengan kadar obat yang sama pada setiap pemakaian. Krim merupakan suatu sediaan yang cara pemakaiannya adalah dioleskan, sehingga dengan tercapainya homogenitas semua formula, bagian zat aktif akan memiliki kesempatan yang sama untuk menempati tempat terapi (30).

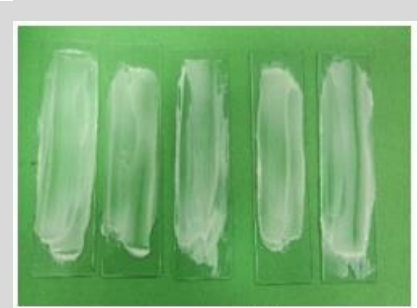

(A)

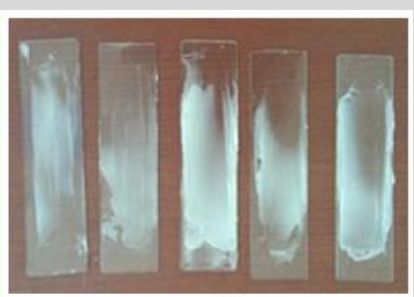

(B)
Gambar 4. Hasil uji homogenitas (A) sebelum Cycling test; (B) setelah Cycling test

\section{Centrifugal Test}

Centrifugal test atau uji mekanik merupakan salah satu pengujian kestabilan krim dengan melihat pengaruh mekanik terhadap pemisahan fase. Centrifugal test dilakukan terhadap semua formula krim etosom asam kojat yang baru dibuat. Pengaruh mekanik ini memberikan gambaran terhadap besarnya pengaruh gaya gravitasi terhadap penyimpanan krim selama satu tahun (24).

Hasil pengamatan menunjukkan tidak terjadinya pemisahan fase pada semua formula krim setelah dilakukan Centrifugal test. Tidak adanya pemisahan fase pada sediaan krim disebabkan surfaktan yang digunakan mampu melindungi tetesan-tetesan minyak pada sediaan krim sehingga fase minyak dan fase air tercampur dengan baik (33). Kestabilan sediaan krim berhubungan dengan daya simpan sediaan krim. Hasil yang diperoleh dapat diduga bahwa sediaan krim etosom asam kojat memiliki daya simpan selama satu tahun (24). Hal tersebut disebabkan tidak terjadi pemisahan fase setelah diberikan efek gaya sentrifugal yang diberikan oleh sentrifugator

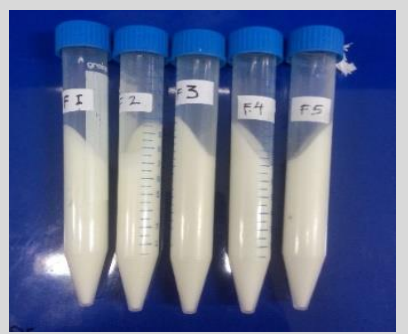

Gambar 5. Hasil Uji Centrifugal Test krim etosom asam kojat

\section{KESIMPULAN}

Etosom asam kojat dapat diformulasi dalam bentuk sediaan krim yang stabil dengan menggunakan kombinasi emulgator tween 80 dan span 80 pada konsentrasi $3 \%$.

\section{DAFTAR PUSTAKA}

1. Purwaningsih, S., Ella S., dan Tika A. B. (2014) Formulasi Skin Lotion dengan Penambahan Karagenan dan Antioksidan Alami dari Rhizophora mucronata Lamk., Jurnal Akuatika, Vol. V(1), hal. 55-62

2. Nisa, M., Radhia R, Sahibuddin A. G., Fatima, Aisyah F., dan Nursamsiar (2013) Uji Efektifitas Beberapa Senyawa Sebagai Peningkat Penetrasi Terhadap Laju Difusi Krim Asam Kojat Tipe Minyak dalam Air Secara in Vitro, Pharmacy, Vol.10 (1), ISSN: 1693-3591.

3. Sudharmono, A. (2005) Penatalaksanaan Hiperpigmentasi Wajah, Majalah Kedokteran Indonesia, Vol. 55 (3)

4. Bandem, A. W. (2013) Analisis Pemilihan Terapi Kelainan Kulit Hiperpigmentasi, Medical Review, vol. 26 (2)

5. Hakim, E. H., Yana M. S., Lia D. J., dan Didin M. (2008) Aktifitas Antioksidan dan Inhibitor Tirosinase Beberapa Stilbenoid dari Tumbuhan Moraceae dan Dipterocarpaceae yang Potensial untuk Bahan Kosmetik, Jurnal Matematika dan Sains, Vol. 13 (2).

6. Ekpunobi, U. E., E.O. Okonkwo, C.V. Udeh, A.S. Ogbuagu, dan C.B. Duru. (2014) Determination of hydroquinone and mercury concentrations in some skin lightening lotions and creams sold in Southeastern Nigeria, International Journal of Biotechnology Research, Vol. 2(1), ISSN: 23283505.

7. Majeed, M. (2008) Anatomi Fisiologi Kulit, Sabinsa Corporation, Jakarta.

8. Kamakshi, R. (2012) Fairness Via Formulations: A Review of Cosmetic Skin Lightening Ingredients, Journal Cosmetic Science, Vol. 63.

9. Fatmawaty, A, Apolarosa T., Radhia R., dan Michrun N. (2012) Formulasi, Evaluasi Fisik dan Permeasi Krim Pemutih Asam Kojat dengan Variasi Enhancer, Majalah Farmasi dan Farmakologi, Vol. 16 (3).

10. Gazali, M., Neviaty P. Z., dan Irmanida B. (2014) Potensi Limbah Kulit Buah Nyirih Xylocarpus granatum Sebagai Inhibitor Tirosinase, Depik, Vol. 3 (3), hal. 187-194

11. Dave, V., Ashutosh Pareek, dan Sarvesh Paliwal. (2012) Ethosome: A Novel Approach Of Transdermal Drug Delivery System, International Journal of Advanced Research In Pharmaceutical And Bioscience, Vol.2 (4), ISSN: $2277-6222$

12. Rakesh, R., dan K. R. Anoop. (2012) Ethosomes oor Transdermal and Topical Drug Delivery, International Journal of Pharmacy and Pharmaceutical Sciences Vol 4 (3), ISSN: 0975-1491.

13. Rathore, G. S., Yuvraj S. T., dan Anshu S. (2015) Fluconazole Loaded Ethosomes Gel and Liposomes Gel: An Updated Review for the Treatment of Deep Fungal Skin Infection, The Pharmaceutical and Chemical Journal, Vol. 2 (1), ISSN: 2349-7092.

14. Riski, R., dan Fitriyanti J. S., 2015, Formulasi Krim Anti Jerawat Dari Nanopartikel Kitosan Cangkang Udang Windu (Penaeusmonodon), JF FIK UINAM, Vol. 3 (4), hal. 153-161

15. Novianti, A., 2017, Preparasi Asam Kojat Dalam Vesikel Etosom Dengan Variasi Konsentrasi Etanol dan Fosfatidilkolin, Skripsi, Universitas Halu Oleo, Kendari.

16. Jeswani, G., dan Swarnlata S., 2014, Topical Delivery of Curcumalonga Extract Loaded Nanosized Ethosomes to Combat Facial Wrinkles, Journal of Pharmaceutics \& Drug Delivery Research, Vol. 3 (1), hal. 2-8.

17. Yanhendri, dan Satya W. Y., 2012, Berbagai Bentuk Sediaan Topikal dalam Dermatologi, $C D K-194$, Vol. 39 (6), hal. 423-430.

18. Sharon, N., Syariful Anam, dan Yuliet. (2013) Formulasi Krim Antioksidan Ekstrak Etanol Bawang Hutan (Eleutherine palmifolia L. Merr), Online Jurnal of Natural Science, Vol. 2(3), ISSN: 2338-0950, hal. 111-122.

19. Pakki, E., Sartini, Rosany, T. dan Nur Laila M., 2009, Formulasi dan Evaluasi Kestabilan Fisik Krim Antioksidan Ekstrak Biji Kakao (Theobroma cacao L.), Majalah Farmasi dan Farmakologi, 13(2), hal. 1-7

20. Safitri, N. A., Oktavia Eka P., dan Valentina Y., 2014, Optimasi Formula Sediaan Krim Ekstrak Stroberi (Fragaria x ananassa) sebagai Krim Anti Penuaan, Majalah kesehatan FKUB, Vol. 1 (4), hal. 235-246

21. Erawati, E., Dina Pratiwi, dan Mohammad Zaky. (2016) Pengembangan Formulasi dan Evaluasi Fisik Sediaan Krim Ekstrak Etanol 70\% Daun Labu Siam (Sechium Edule Jacq. Swatz), Farmagazine, Vol. 3 (1), hal. 11 - 20. 
22. Aswal, A., Mohini K., dan Abhiram R., 2013, Preparation and Evaluation of Polyherbal Cosmetic Cream, Der Pharmacia Lettre, Vol. 5 (1), hal. 83-88.

23. Nurlaela, E., Nining S., dan Azis I., 2012, Optimasi Komposisi Tween 80 dan Span 80 Sebagai Emulgator dalam Repelan Minyak Atsiri Daun Sere (Cymbopogon citratus (D.C) Stapf) Terhadap Nyamuk Aedes Aegypti Betina Pada Basis Vanishing Cream dengan Metode Simplex Lattice Design, Jurnal Ilmiah Kefarmasian, Vol. 2 (1), hal. 41 - 54

24. Elya, B., Dewi, R, dan Budiman, M., H., 2013, Antioxidant Cream of Solanum lycopersicum L., International Journal of Pharmtech Research, Coden(USA) Vol. 5(1).

25. Patty, P.V. (2015) Pengaruh Lama Fermentasi Terhadap Ranciditas Minyak Kelapa Yang Diproduksi Secara Tradisional, Biopendix, Vol. 1(2)

26. Wu, Y, S. Iglauer, P. Shuler, Y. Tang, dan W. A. Goddard. (2010) Alkyl Polyglycoside-Sorbitan Ester Formulations for Improved Oil Recovery, Environmental/Technical Chemistry, hal. 280-287.

27. Tranggono, R. I., dan Fatma L. (2007) Buku Pegangan Ilmu Pengetahuan Kosmetik, Gramedia Pustaka Utama, Jakarta.

28. Levin, J., dan Maibach H., 2007, Human Skin Buffering Capacity, Journal of Skin Research and Technology, hal. 121-126.
29. Fitriansyah, S. N., dan Dolih G. (2014) Formulasi dan Evaluasi Fisik Sediaan Krim Pelembab Dimethylsilanol Hyaluronate dengan Penambahan Basis Nano dan Fase Minyak Kelapa Murni, Indonesian Journal of Pharmaceutical Science and Technology, Vol. 3 (1), hal. 31-41.

30. Swastika, A Mufrod, dan Purwanto. (2013) Antioxidant Activity of Cream Dosage Form of Tomato Extract (Solanum lycopersicum L.), Traditional Medicine Journal, Vol. 18 (3), hal. 132-140.

31. Dewi, R., Effionora A., dan Yunita K. S. (2014) Uji Stabilitas Fisik Formula Krim yang Mengandung Ekstrak Kacang Kedelai (Glycine max), Pharmacy Science Researc, Vol. 1(3)

32. Lachman, L., Herbert A. L., dan Joseph L. K. (2008) Teori dan Praktek Farmasi Industri Jilid II, Jakarta.

33. Gennaro, A. R, 2005, Remington and Practice of Pharmacy, 18th Edition Philadelphia College of Pharmacy and Science, Philadelphia, hal. 301-302

34. Luthfiyana, N., Nurjanah, Mala N., Effionora A., dan Taufik H. (2016) Rasio Bubur Rumput Laut Eucheuma cottonii dan Sargassum Sp. Sebagai Formula Krim Tabir Surya, JPHI, Vol. 19 (3), hal. 183-195. 